\title{
Erythema migrans in Lyme disease
}

\author{
David A. Wetter MD, Colin A. Ruff MD
}

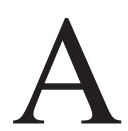

47-year-old man presented with a twoweek history of an enlarging red patch on his left thigh, associated with lowgrade fever. Although he had recently spent time outdoors while at his cabin in northern Minnesota, he did not recall any injury or insect bite to his leg. His thigh had a large patch of homogeneous erythema with central darkening and focal areas of hemorrhage, vesiculation and necrosis (Figure 1). Microscopic examination of a skin biopsy specimen showed papillary edema with extravasated red blood cells, and dense superficial and deep perivascular and interstitial mononuclear inflammation of the dermis. Stains (including a Gram stain) were negative for microorganisms, and tissue cultures were negative for bacterial, fungal and mycobacterial infection. Polymerase chain reaction testing of the skin biopsy tissue was positive for Borrelia burgdorferi. Because we had suspected Lyme disease, the patient had already been given a three-week course of doxycycline, and his fever and skin findings resolved.

Although erythema migrans, the earliest cutaneous finding of Lyme disease, may present as slowly expanding erythema with partial central clearing forming the classic "target lesion," homogeneous erythema may be the most common presentation in North America, with target lesions reported in less than $10 \%$ of instances. ${ }^{1}$ About $50 \%$ of people with Lyme disease also have influenza-like symptoms. ${ }^{1}$ Primary lesions related to erythema migrans are usually more than $5 \mathrm{~cm}$ in diameter. ${ }^{2}$ Central hemorrhage, necrosis and bulla formation, as seen in our patient, occur less commonly. ${ }^{3}$ A skin biopsy and tissue culture can help to exclude infection in equivocal cases. Although serologic testing (and, less commonly, polymerase chain reaction testing and tissue culture) can be helpful in the diagnosis of Lyme disease, the distinctive features of erythema migrans allow a clinical diagnosis in the absence of laboratory confirmation. ${ }^{2}$ Because serologic testing in the initial two weeks of infection has a sensitivity

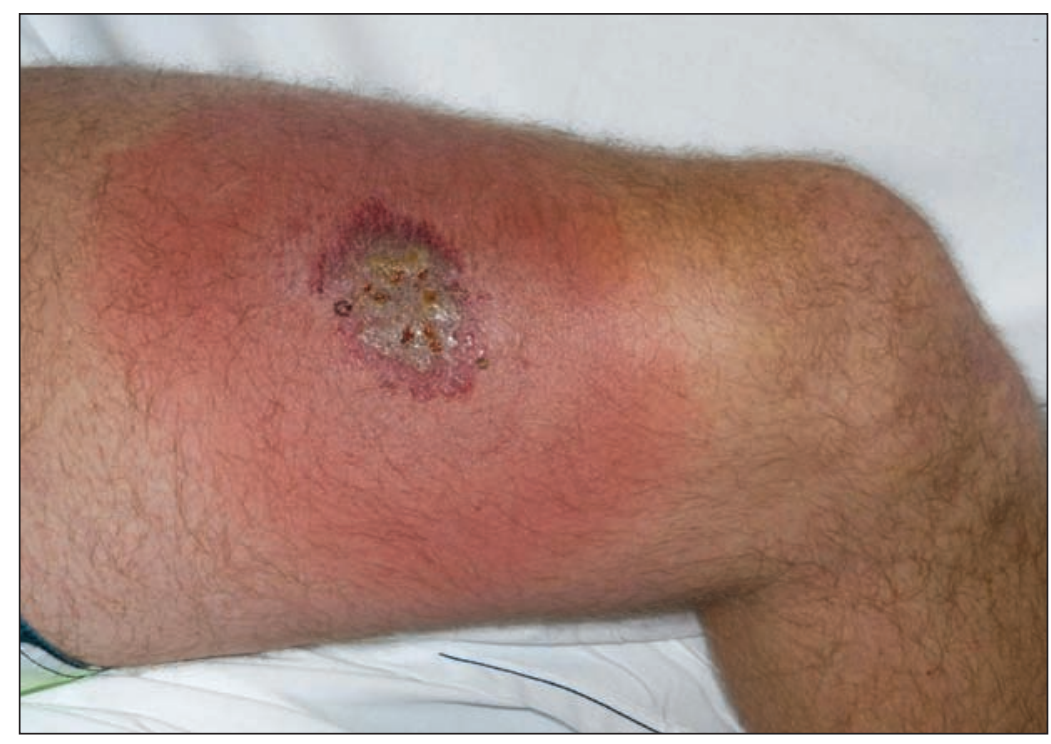

Figure 1: Homogeneous erythematous patch with central darkening and focal areas of hemorrhage, vesiculation and necrosis on the left thigh of a 47-yearold man, who also presented with a two-week history of low-grade fever after spending time outdoors in northern Minnesota.

of only $40 \%$, patients from endemic areas with clinically suspected Lyme disease should receive appropriate antibiotics such as doxycycline (100 $\mathrm{mg}$ twice per day) or amoxicillin (500 $\mathrm{mg} 3$ times per day) for 14 days. ${ }^{2.4}$

\section{References}

1. Smith RP, Schoen RT, Rahn DW, et al. Clinical characteristics and treatment outcome of early Lyme disease in patients with microbiologically confirmed erythema migrans. Ann Intern Med 2002;136:421-8.

2. Wormser GP, Dattwyler RJ, Shapiro ED, et al. The clinical assessment, treatment, and prevention of Lyme disease, human granulocytic anaplasmosis, and babesiosis: clinical practice guidelines by the Infectious Diseases Society of America. [published erratum appears in Clin Infect Dis 2007;45:941]. Clin Infect Dis 2006;43:1089-134.

3. Asbrink E, Hovmark A. Lyme borreliosis. In: Freedberg IM, Eisen AZ, Wolff K, et al., editors. Fitzpatrick's dermatology in general medicine. Vol 2. 6th ed. New York (NY): McGraw-Hill, Medical Publishing Division; 2003. p. 1972-80.

4. Nowakowski J, Schwartz I, Liveris D, et al. Laboratory diagnostic techniques for patients with early Lyme disease associated with erythema migrans: a comparison of different techniques. Clin Infect Dis 2001;33:2023-7.
Competing interests: None declared.

This article has been peer reviewed.

\section{Affiliation:}

From the Department of Dermatology, Mayo Clinic, Rochester, Minn.

Correspondence to: Dr. David A. Wetter, wetter.david@mayo.edu

CMAJ 2011. DOI:10.1503 /cmaj.101533 